\title{
Guest-Host Inclusion Complex Formation of 2-, 3-, and 4-Aminobenzoic Acids with Native and Modified Cyclodextrins
}

\author{
N. Rajendiran", J. Thulasidhasan and M. Jude Jenita \\ Department of Chemistry, Annamalai University, Annamalai Nagar - 608002, Tamilnadu, India \\ *Corresponding author: drrajendiran@rediffmail.com \\ Phone: +9194866 28800.
}

Keywords: Cyclodextrins, Aminobenzoic acid, Inclusion complex, Intramolecular charge transfer

\begin{abstract}
The inclusion complexation of 2-aminobenzoic acid (2ABA), 3-aminobenzoic acid (3ABA), and 4-aminobenzoic acid (4ABA) with $\alpha$-cyclodextrin $(\alpha-C D), \beta$-cyclodextrin $(\beta-C D)$, hydroxypropyl- $\alpha$-cyclodextrin (HP- $\alpha-C D$ ) and hydroxypropyl- $\beta$-cyclodextrin (HP- $\beta$-CD) were studied in buffer solutions of different $\mathrm{pHs}(\mathrm{pH} \sim 1$ and $\mathrm{pH} \sim 7)$ and it was carried out using UV-Visible, steady-state and time-resolved fluorescence. Dual fluorescence was observed for all the compounds in aqueous and $\mathrm{CD}$ medium. All the ABAs forms 1:1 inclusion complex at $\mathrm{pH} \sim 1$ solution and mixture of 1:1 and 1:2 inclusion complex at $\mathrm{pH} \sim 7$. With $\mathrm{CDs}$, dual luminescence appeared at $\mathrm{pH} \sim 1$ indicates, both $\mathrm{NH} 3+$ and $\mathrm{COOH}$ groups are present in the interior of the CDs cavities. FT-IR, 1H NMR, results suggest ABAs formed a stable inclusion complex with the CDs.
\end{abstract}

\section{Introduction}

There have been several studies [1-6] on the electronic spectra of aminobenzoic acids (ABAs). Doub and Vanderbelt recorded the absorption spectra at $\mathrm{pH} \sim 3$ to $\mathrm{pH} \sim 10$. Kopylova et al [3] have reported the absorption spectra in aqueous solutions. In 1963, the effect of hydrogen bonding between aminobenzoic acids and the solvent molecules on the spectral shifts has been discussed by Mataga [4]. Tramer [5] has studied the absorption and fluorescence spectra of N-methyl anthranilic acid and N,N-dimethyl anthranilic acid in various solvents. In his work, the problem of the tautomeric equilibria of zwitter ions in the $S_{1}$ and $T_{1}$ states was discussed. In 1986, Jain et al [6] studied the absorption and emission spectra of aminobenzoic acids in methyl cyclohexane, acetonitrile, methanol solvents and at different $\mathrm{pH}(1 \mathrm{~N} \mathrm{HCl}$ and $1 \mathrm{~N} \mathrm{NaOH})$. The results have been discussed by the CNDO/S calculation method.

Rajendiran et al [7-9] have studied the absorption and fluorescence spectra of the 2ABA, $3 \mathrm{ABA}$ and $4 \mathrm{ABA}$ in different solvents, $\mathrm{pH}$ and $\beta-\mathrm{CD}$ in great detail. Kim et al, Jiang et al [10] and others [11] demonstrated that the TICT emission of $4-\left(\mathrm{N}, \mathrm{N}^{-}\right.$diethylamino $)$and $4-(\mathrm{N}, \mathrm{N}-$ dimethylamino)benzoic acid is enhanced on complexation with $\alpha$-CD. They have attributed this property to the reduced polarity rather than to the restricted molecular motion inside the CD cavity. Furthermore, the restrictive environment of the CD's is known to affect the excited state geometry change [7] which is closely related to the formation of the excited ICT state. Thus, there still remain several arguments on whether the ICT emission is always enhanced upon formation of any CD complexes and to the excited state geometry change is influenced by the CD complex formation. It is necessary, therefore, to study the inclusion interaction of different CDs with 2ABA, 3ABA and $4 \mathrm{ABA}$ molecules. From this point of view, it would be interesting to see how the $\alpha-C D, \beta-C D$, HP- $\alpha-C D$ and HP- $\beta-C D$ systems affect the ICT emission and the excited state geometry change of the ICT molecule. The present study reports our extensive measurements on the absorption, emission spectra of $2 \mathrm{ABA}, 3 \mathrm{ABA}$ and $4 \mathrm{ABA}$ in different $\mathrm{pH}$ with $\alpha-\mathrm{CD}, \beta-\mathrm{CD}, \mathrm{HP}-\alpha-\mathrm{CD}$ and HP$\beta$-CD. This is extension of our earlier work [9-24]. 


\section{Experimental}

\subsection{Instruments}

Absorption spectral measurements were carried out with a Shimadzu UV 1601 PC model UV-Visible spectrophotometer and fluorescence measurements were made with a Shimadzu RF 5301 spectrofluorophotometer. The $\mathrm{pH}$ values in the range 2.0-12.0 were measured on an Elico $\mathrm{pH}$ meter model LI-120.

\subsection{Reagents and materials}

2-Aminobenzoic acid (2ABA), 3-aminobenzoic acid (3ABA), 4-aminobenzoic acid (4ABA), $\alpha$-cyclodextrin, $\beta$-cyclodextrin, HP- $\alpha-C D, H P-\beta-C D$ and all the spectrograde solvents were received from Sigma and Aldrich Chemicals Company and used as such. $\mathrm{pH}$ of solutions within the range 2.0-12.0 was adjusted by the addition of phosphate buffers $\left(10^{-3} \mathrm{M}\right)$ different concentration of $\mathrm{NaOH}-\mathrm{H}_{3} \mathrm{PO}_{4}$ as this amount of buffer do not quench fluorescence of the sample and also do not alter the prototropic equilibrium under study. The solutions were prepared just before each measurement. The concentration of the ABAs solutions was of the order of $2 \times 10^{-4} \mathrm{M}$ to $2 \times 10^{-5} \mathrm{M}$ and the $\mathrm{CD}$ solution was varied from $1 \times 10^{-3} \mathrm{M}$ to $1 \times 10^{-2} \mathrm{M}$.

\section{Result and Discussion}

\subsection{Studies of ABAs with cyclodextrins}

Absorption and fluorescence spectra of 2ABA, 3ABA and 4ABA have been analysed and compared in $\alpha-C D, \beta-C D$, HP- $\alpha-C D$ and HP- $\beta-C D$ solutions. Figs. 1 to 6 depict the absorption and emission maxima of the above ABAs $(2 \times 10-5 \mathrm{M})$ in $\mathrm{pH} \sim 1.0$ (monocation) and $\mathrm{pH} \sim 7.0$ (monoanion) solutions containing different concentrations of $\alpha-\mathrm{CD}, \beta-\mathrm{CD}, \mathrm{HP}-\alpha-\mathrm{CD}$ and HP- $\beta-\mathrm{CD}$. In neutral solutions ( $\mathrm{pH} \sim 7$ ), all the ABAs exist as carboxylic anions.
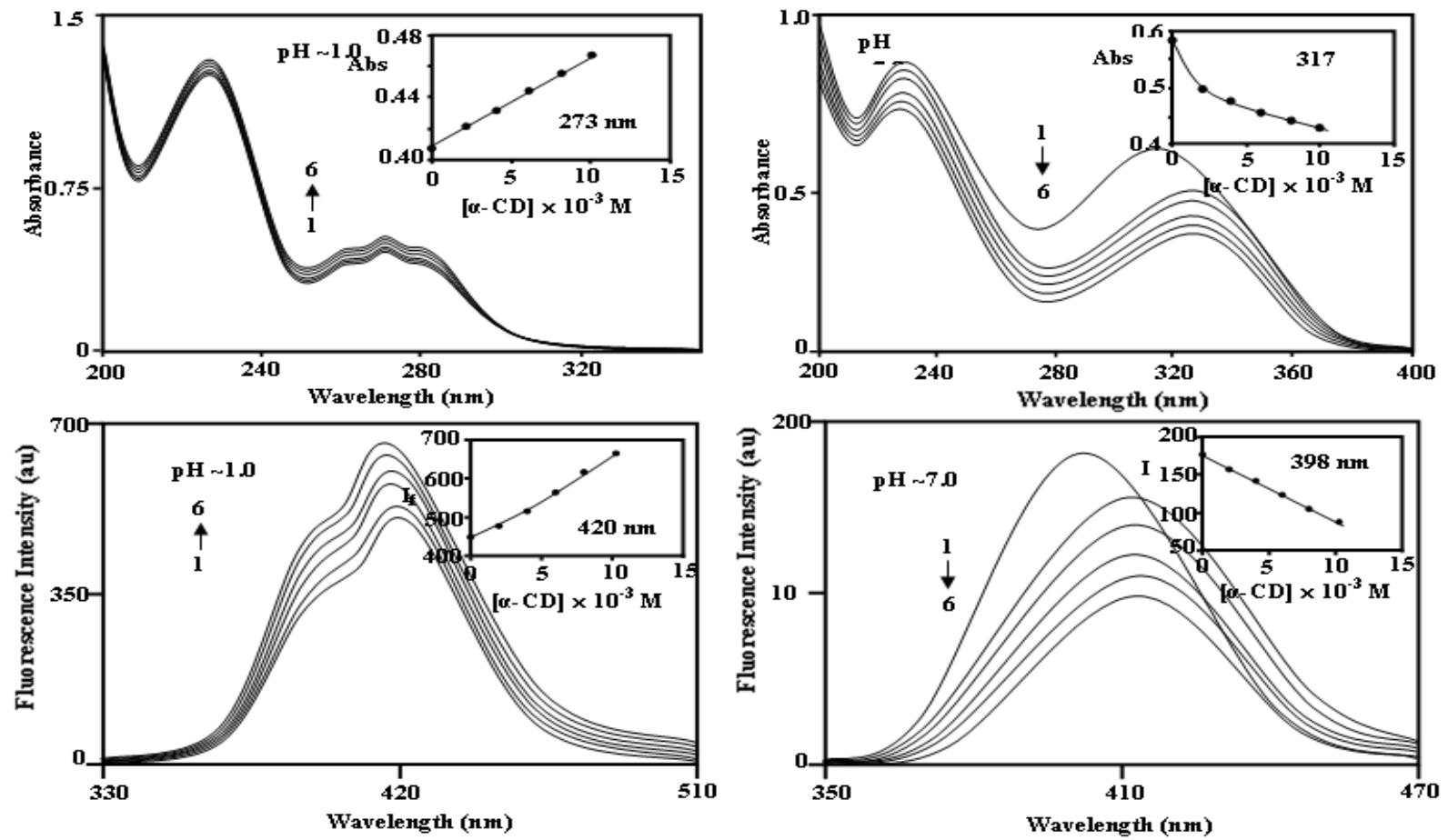

Fig 1. Absorption and fluorescence spectra of $2 \mathrm{ABA}$ with various $\alpha-\mathrm{CD}$ concentrations (M) at different pH: (1) 0, (2) 0.002, (3) 0.004, (4) 0.006, (5) 0.008 and (6). 0.01. Insert Fig.: absorbance/fluorescence intensity vs. [ $\alpha-C D]$. 

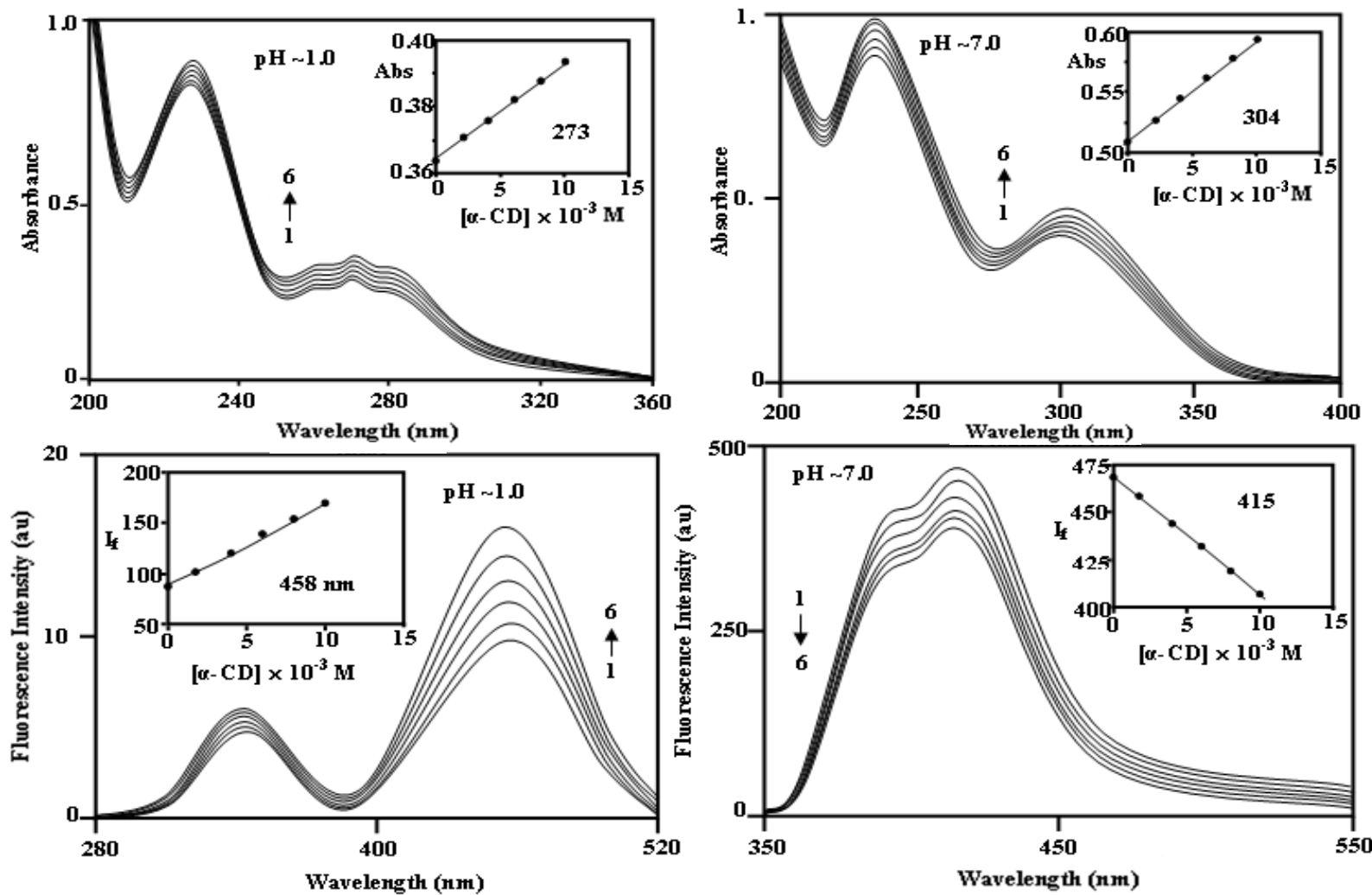

Fig 2. Absorption and fluorescence spectra of $3 \mathrm{ABA}$ with various $\alpha-\mathrm{CD}$ concentrations $(\mathrm{M})$ at different pH: (1) 0, (2) 0.002, (3) 0.004, (4) 0.006, (5) 0.008 and (6). 0.01. Insert Fig.: absorbance/fluorescence intensity vs. [ $\alpha-C D]$.
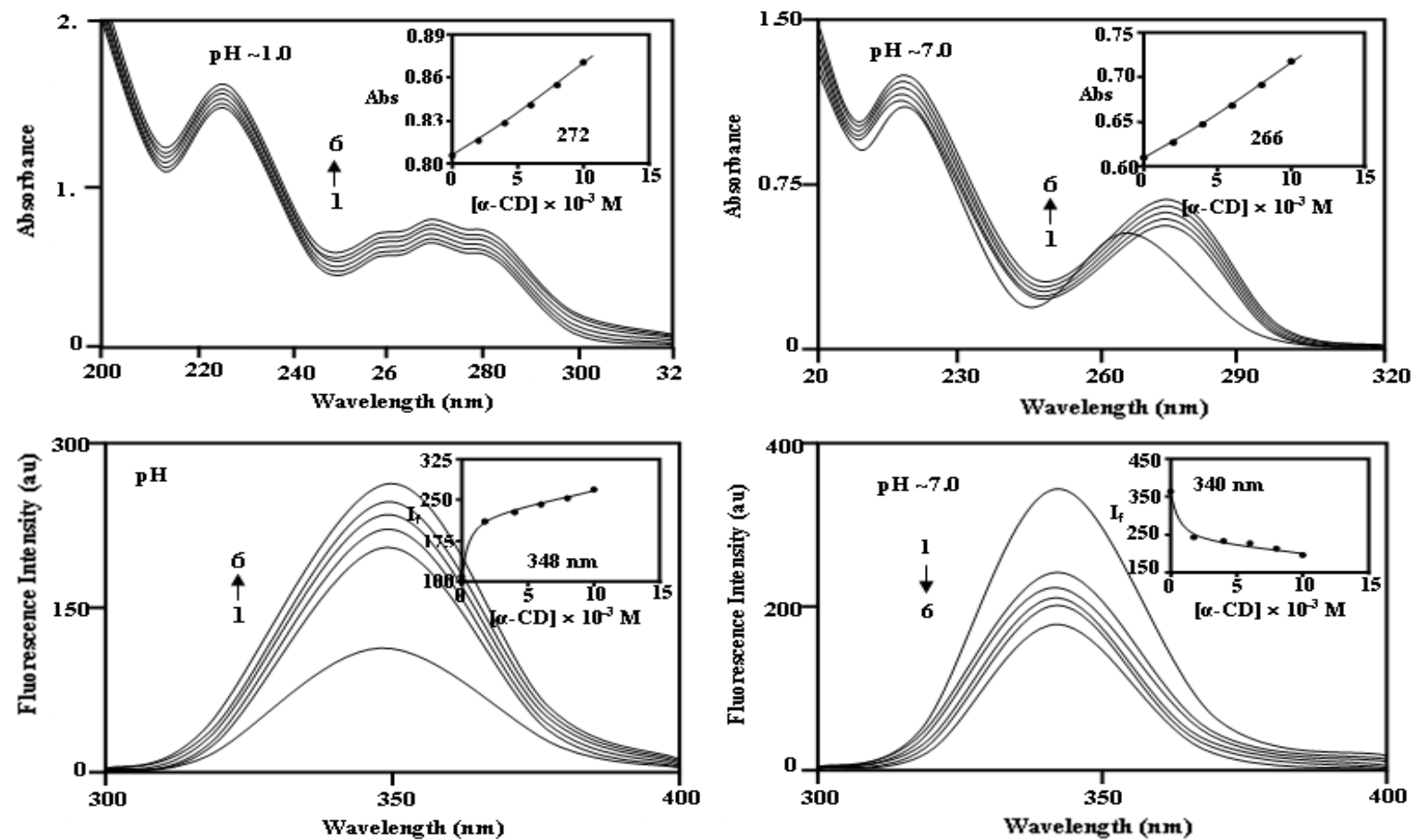

Fig. 3. Absorption and fluorescence spectra of $4 \mathrm{ABA}$ with various $\alpha-\mathrm{CD}$ concentrations $(\mathrm{M})$ at different pH: (1) 0, (2) 0.002, (3) 0.004, (4) 0.006, (5) 0.008 and (6). 0.01. Insert Fig.: absorbance/fluorescence intensity vs.[ $\alpha-C D]$. 

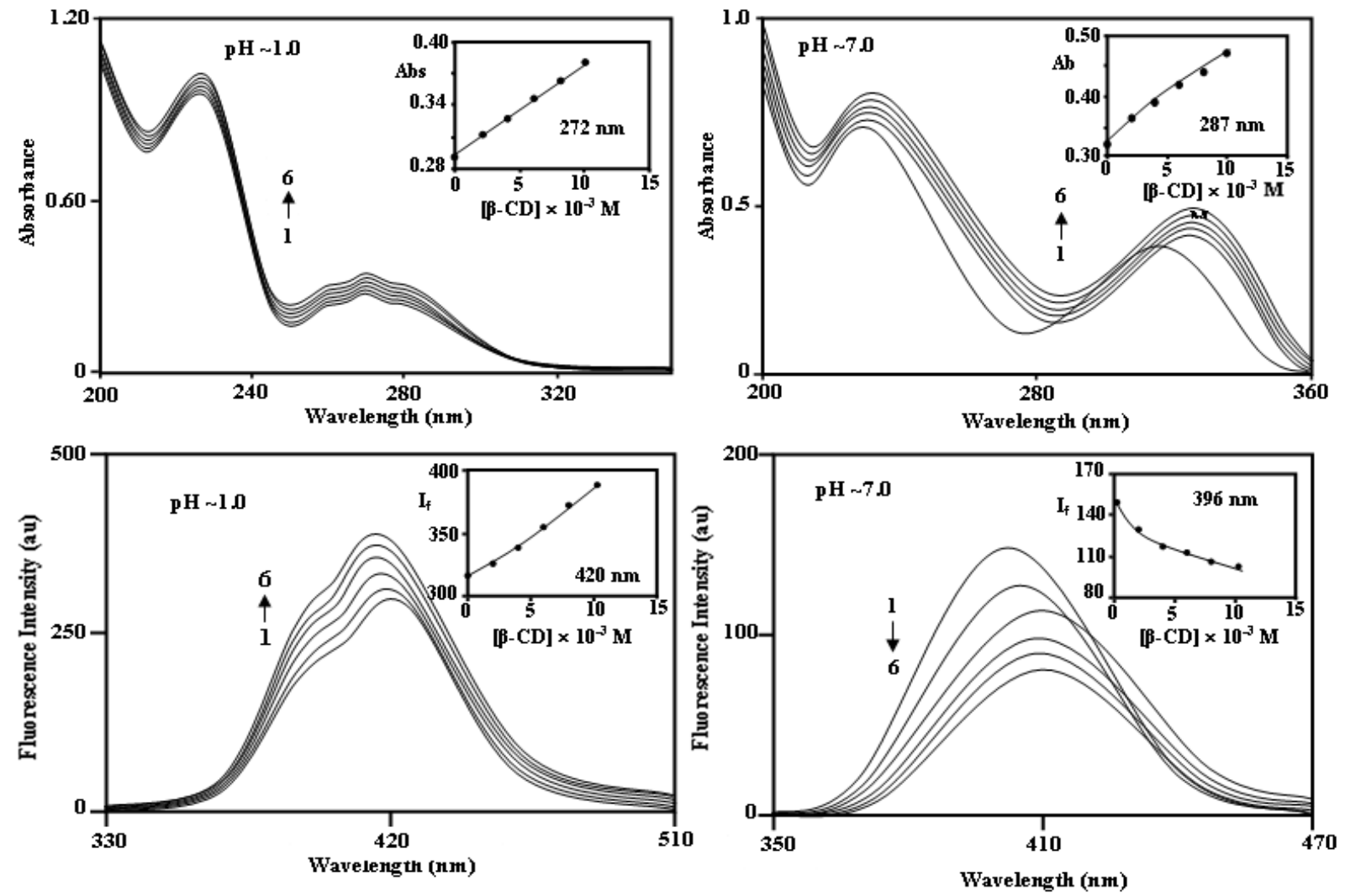

Fig 4. Absorption and fluorescence spectra of $2 \mathrm{ABA}$ with various $\beta$-CD concentrations $(\mathrm{M})$ at different pH: (1) 0, (2) 0.002, (3) 0.004, (4) 0.006, (5) 0.008 and (6). 0.01. Insert Fig.: absorbance/fluorescence intensity vs. [ $\beta-\mathrm{CD}]$.
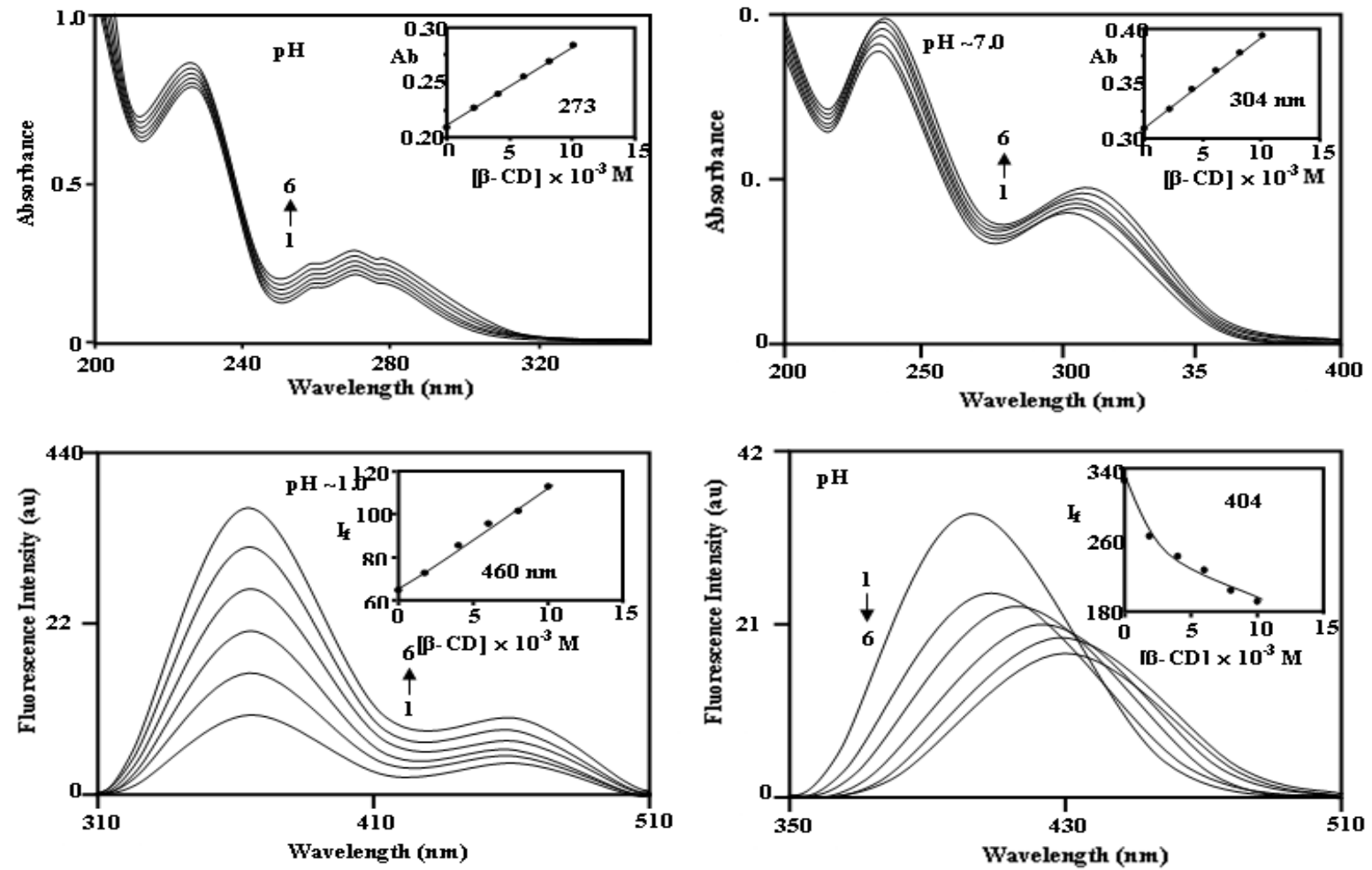

Fig 5. Absorption and fluorescence spectra of $3 \mathrm{ABA}$ with various $\beta$-CD concentrations $(\mathrm{M})$ at different pH: (1) 0, (2) 0.002, (3) 0.004, (4) 0.006, (5) 0.008 and (6). 0.01. Insert Fig.: absorbance/fluorescence intensity vs. [ $\beta-\mathrm{CD}]$. 

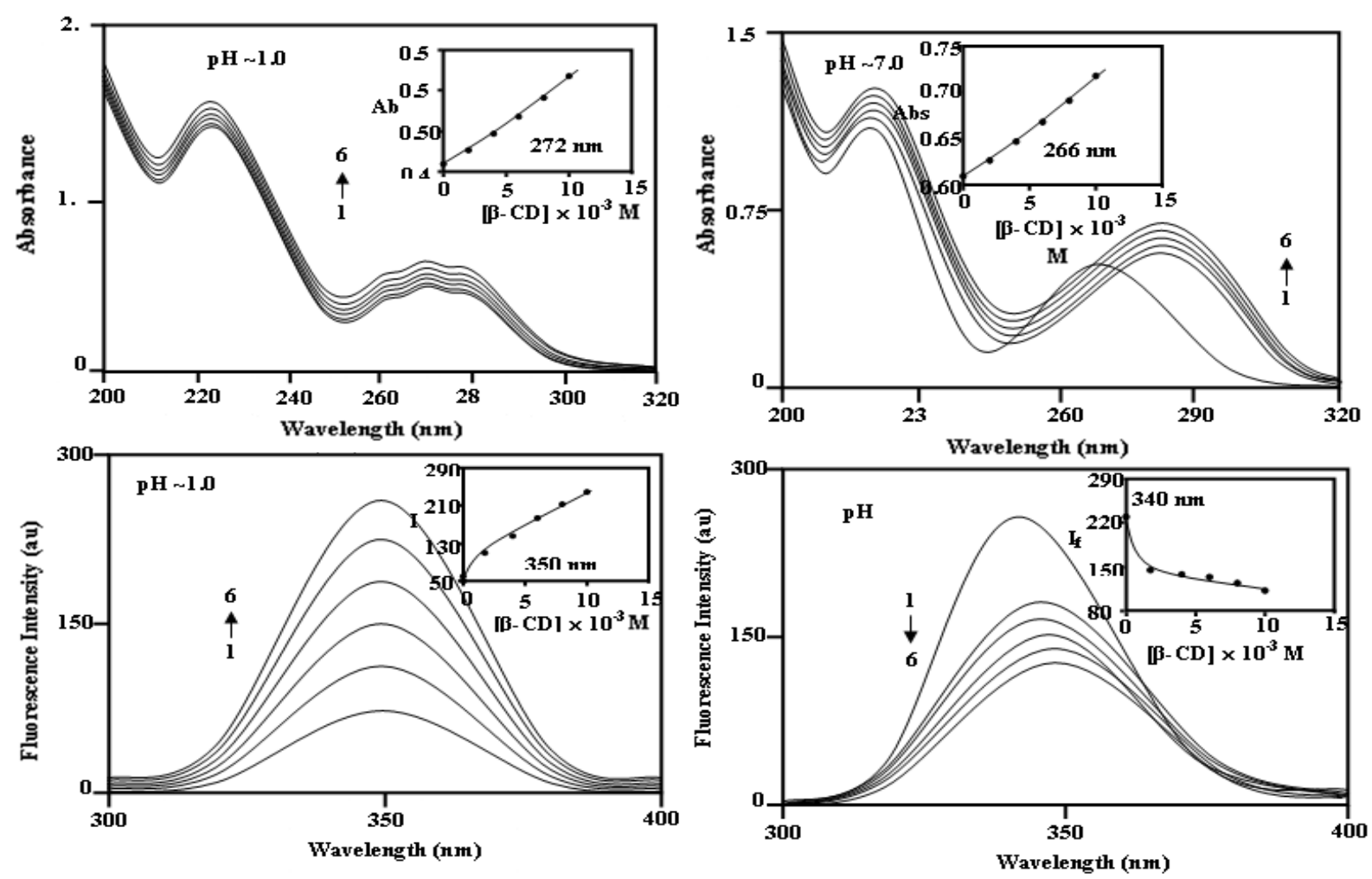

Fig. 6. Absorption and fluorescence spectra of $4 \mathrm{ABA}$ with various $\beta-\mathrm{CD}$ concentrations $(\mathrm{M})$ at different pH: (1) 0, (2) 0.002, (3) 0.004, (4) 0.006, (5) 0.008 and (6). 0.01. Insert Fig.: absorbance/fluorescence intensity vs. [ $\beta-\mathrm{CD}]$.

Hence, we also recorded the absorption and emission spectra at $\mathrm{pH} \sim 1$. In the absorption spectra, the monocation and monoanion maxima of the ABAs are considerably different. The absorption maxima of all the ABAs appear at the same wavelength (at $272 \mathrm{~nm}$ ) in $\mathrm{pH} \sim 1$ and the shapes of the spectra are also similar to each other. But in $\mathrm{pH} \sim$, the absorption maxima of $2 \mathrm{ABA}$, $3 \mathrm{ABA}$ and $4 \mathrm{ABA}$ appear at $330 \mathrm{~nm}, 306 \mathrm{~nm}$ and $276 \mathrm{~nm}$ respectively. At $\mathrm{pH} \sim 1$, in the presence of $\mathrm{CDs}$, no significant absorption spectral change is observed in all the ABAs, whereas it is seen to undergo a marginal red shift at $\mathrm{pH} \sim 7$.

At $\mathrm{pH} \sim 1$, the absorption spectra of all the ABAs do not show any change even in the presence of the highest concentrations of CDs used $\left(1 \times 10^{-2} \mathrm{M}\right)$ whereas a regular red shift observed at $\mathrm{pH} \sim 7$. Interestingly, in the presence of all the four $\mathrm{CDs}$, at $\mathrm{pH} \sim 1$, the fluorescence characteristics of the three ABAs are seen to undergo drastic change (Figs. 1 to 6). In the presence of $4 \times 10^{-3} \mathrm{M} \mathrm{CD}$ and above, the fluorescence maxima of the ABAs are red shifted in $\mathrm{pH} \sim 1$, as compared to that $\mathrm{pH} \sim 7$. In $2 \mathrm{ABA}$ and $3 \mathrm{ABA}$, when compared to water, a dual emission is noticed in $\mathrm{pH} \sim 1$. However, in all the CDs and in both pHs, 4ABA gives single emission maximum only. The fluorescence intensities $\left(\mathrm{I}_{\mathrm{F}}\right)$ of all the ABAs in the $\mathrm{CD}$ solutions decreased along with red shift at $\mathrm{pH} \sim 7$, but in $\mathrm{pH} \sim 1$, the $\mathrm{I}_{\mathrm{F}}$ values increased at the same wavelength. The emission intensities of $2 \mathrm{ABA}$ in $\mathrm{pH} \sim 7$ initially decreased with increasing $\beta$-CD/HP- $\beta$-CD concentrations, whereas above $4 \times 10^{-3} \mathrm{M} \beta-\mathrm{CD} / \mathrm{HP}-\beta-\mathrm{CD}$ concentrations, the emission intensities increased. However, with $\alpha-\mathrm{CD} / \mathrm{HP}-\alpha-\mathrm{CD}$ solutions, the emission intensities of all the ABAs increased. Further, the absorbance and fluorescence intensity changes were different in $\alpha$-CDs and $\beta$-CDs, which indicate all the CDs form different types of inclusion complexes [9-24].

At $\mathrm{pH} \sim 7$, the emission maxima of the ABAs in the four CDs solutions were red shifted suggesting that COO- group is located within the non-polar cavity of the CDs, whereas NH2 group is located in polar medium. This prediction is based on the following reasons: the large rim of the CD contains many secondary hydroxyl groups and thus provides an environment qualitatively similar to polyhydroxyl alcohols. In all the CD medium, no significant spectral shifts observed at $\mathrm{pH} \sim 1$ clearly establish that carboxyl group is deeply entrapped in the CDs cavities. 
The results shown in Figs. 1 to $6(\mathrm{pH} 1)$ indicate that the ICT behavior of 2ABA and 3ABA is significantly enhanced by the formation of the inclusion complexes. In $\mathrm{pH} \sim 1$, above $6 \times 10^{-3} \mathrm{M}$ CDs concentrations, the dual fluorescence typical of intramolecular charge transfer (ICT) can be seen easily. This is because the polarity and viscosity variations may play a more important role in the change in the ICT behavior of $2 \mathrm{ABA}$ and $3 \mathrm{ABA}$. This influence could be the result of the altered dissociation of $\mathrm{COOH}$ group in both ABAs. In $\mathrm{pH} \sim 1$ solutions, two bands could be observed at $370 \mathrm{~nm}$ (normal emission, LE) and $460 \mathrm{~nm}$ (ICT). Upon addition of the CDs in $\mathrm{pH} \sim 1$, the LE band was strongly enhanced along with a small enhancement of ICT without any spectral shifts whatsoever. Compared to $\mathrm{pH} \sim 7$, in $2 \mathrm{ABA}$ and $3 \mathrm{ABA}$, the difference in the spectral change at $\mathrm{pH} \sim 1$ suggests that the structural geometry of the inclusion complexes was different in terms of orientation of guest molecule [6, 7]. Possibly the ICT behavior of 2ABA and 3ABA is dramatically affected by the formation of different types of complexes within the non-polar cavity of CD. It is well known, in CD solution hydrophobicity is the driving force for encapsulation of the molecule inside the cavity and naturally the hydrophobic part $(\mathrm{COOH})$ would like to go inside the deep core of the non-polar cavity and the amino group will be the hydrophilic part of the CD cavity.

Inside the $\mathrm{CD}$ cavities, $2 \mathrm{ABA}$ and $3 \mathrm{ABA}$ feel much less polar environment and the normal emission (through ICT) is restricted which also causes an enhancement of the normal band. Further, the geometrical restriction of the cavity would restrict the free rotation of the amino or carboxyl group inside the CD cavity and thus hinder the formation of ICT state causing an enhancement of normal LE band. This is reasonable, because at $\mathrm{pH} \sim 7$, amino group is more polar and can form hydrogen bonds with either - $\mathrm{OH}$ groups on the $\mathrm{CD}$ cavity rim or bulk water molecules or both.

Above $4 \times 10^{-3} \mathrm{M} \mathrm{CD}$ concentrations (in $\mathrm{pH} \sim 1$ ), the dual fluorescence typical of ICT can be seen easily in 2ABA and 3ABA. Typically, both the LE and the ICT bands were enhanced, and the ICT band was shifted to the blue while the LE band was not shifted. Due to the high polarity of the ICT state, this result should mean that ABA molecules have penetrated into the nonpolar CD cavity and $\mathrm{ABA}: \mathrm{CD}$ inclusion complexes have been formed. The results shown in Figs. 1 to 6 ( $\mathrm{pH} \sim 1$ ) indicate that the ICT behavior of the ortho and meta ABAs in $\alpha$-CDs solution is higher than $\beta$-CDs. Since the cavity size $\alpha$-CDs is smaller than $\beta$-CDs cavity, the ortho and meta ABA molecules are more tightly encapsulated in the $\alpha$-CDs; That is why dual emission can easily be formed in the $\alpha$ $\mathrm{CD} / \mathrm{HP}-\alpha-\mathrm{CD}$ medium. Further, polarity and viscosity variations may play a more important role in the change in the ICT behavior of ortho and meta isomers at $\mathrm{pH} \sim 1$. The ICT band of ortho and meta ABAs was shifted to the red with increasing $\mathrm{CD}$ concentration. This provides strong evidence for the protrusion of the $\mathrm{COOH}$ group into the hydrophobic phase. This is reasonable, because in ortho and meta ABAs, the dual luminescence is not observed in the absence of CD medium. Further, the question is why 4ABA molecule does not give ICT emission in both CDs, is because the size of $4 \mathrm{ABA}$ molecule is smaller than the CD cavity. Hence 4ABA can freely rotate in the CDs cavities.

The association constant for all the ABA:CD inclusion complexes formation has been determined by analysing the changes in the intensities of absorption and fluorescence maxima with the CDs concentration (Table 1). Figs. 7 to 10 show a plot of $1 / \mathrm{I}-\mathrm{I}_{0}$ versus $1 /[\mathrm{CD}]$ and $1 / \mathrm{I}-\mathrm{I}_{0}$ versus $1 /[C D]^{2}$ change in the fluorescence intensities with increasing concentration of the CDs. It is seen from this plot in $\mathrm{pH} \sim 1$, the fluorescence intensities increased along with CDs concentration. However, in $\mathrm{pH} \sim 7$, the emission intensities of ABAs decreased indicating the incorporation of almost all the ABA molecules in the $\mathrm{CD}$ cavity. In the absorption spectra, at $\mathrm{pH} \sim 1$, clear isosbestic points were observed in all the CDs showing well defined 1:1 inclusion complexes were formed between ABAs and CDs. 
Table 1. Binding constant and Gibbs free energy of 2ABA, 3ABA and 4ABA with different $\alpha-C D$ and $\beta$-CD concentrations

\begin{tabular}{|c|c|c|c|c|c|c|c|c|c|}
\hline & & \multicolumn{4}{|c|}{$\alpha-C D / H P \alpha-C D$} & \multicolumn{4}{|c|}{$\beta-C D / H P \beta-C D$} \\
\hline & & \multicolumn{2}{|c|}{$\mathrm{pH} \sim 1$} & \multicolumn{2}{|l|}{$\mathrm{pH} \sim 7$} & \multicolumn{2}{|c|}{$\mathrm{pH} \sim 1$} & \multicolumn{2}{|l|}{$\mathrm{pH} \sim 7$} \\
\hline & & $\lambda_{\mathrm{abs}}$ & $\lambda_{\text {flu }}$ & $\lambda_{\text {abs }}$ & $\lambda_{\text {flu }}$ & $\lambda_{\text {abs }}$ & $\lambda_{\text {flu }}$ & $\lambda_{\mathrm{abs}}$ & $\lambda_{\text {flu }}$ \\
\hline \multirow[t]{2}{*}{$2 \mathrm{ABA}$} & $\mathrm{K}(1: 1) \mathrm{M}^{-1}$ & 320 & 282 & 289 & 574 & 152 & 378 & 210 & 313 \\
\hline & $\begin{array}{c}\Delta \mathrm{G} \mathrm{kJ} \mathrm{mol}^{-1} \\
(-\mathrm{ve})\end{array}$ & 14.53 & 14.21 & 14.27 & 16.00 & 12.65 & 14.95 & 10.77 & 13.76 \\
\hline \multirow[t]{2}{*}{$3 \mathrm{ABA}$} & $\mathrm{K}(1: 1) \mathrm{M}^{-1}$ & 622 & 2743 & 47 & 120 & 157 & 129 & 68 & 95 \\
\hline & $\begin{array}{c}\Delta \mathrm{G} \mathrm{kJ} \mathrm{mol}^{-1} \\
(-\mathrm{ve})\end{array}$ & 16.21 & 19.93 & 9.69 & 12.00 & 12.34 & 12.23 & 10.03 & 17.26 \\
\hline \multirow[t]{2}{*}{$4 \mathrm{ABA}$} & $\mathrm{K}(1: 1) \mathrm{M}^{-1}$ & 680 & 745 & 1933 & 1866 & 33 & 232 & 89 & 212 \\
\hline & $\begin{array}{c}\Delta \mathrm{G} \mathrm{kJ} \mathrm{mol}^{-1} \\
(-\mathrm{ve})\end{array}$ & 16.43 & 16.66 & 19.00 & 18.87 & 8.81 & 13.82 & 11.31 & 13.51 \\
\hline
\end{tabular}
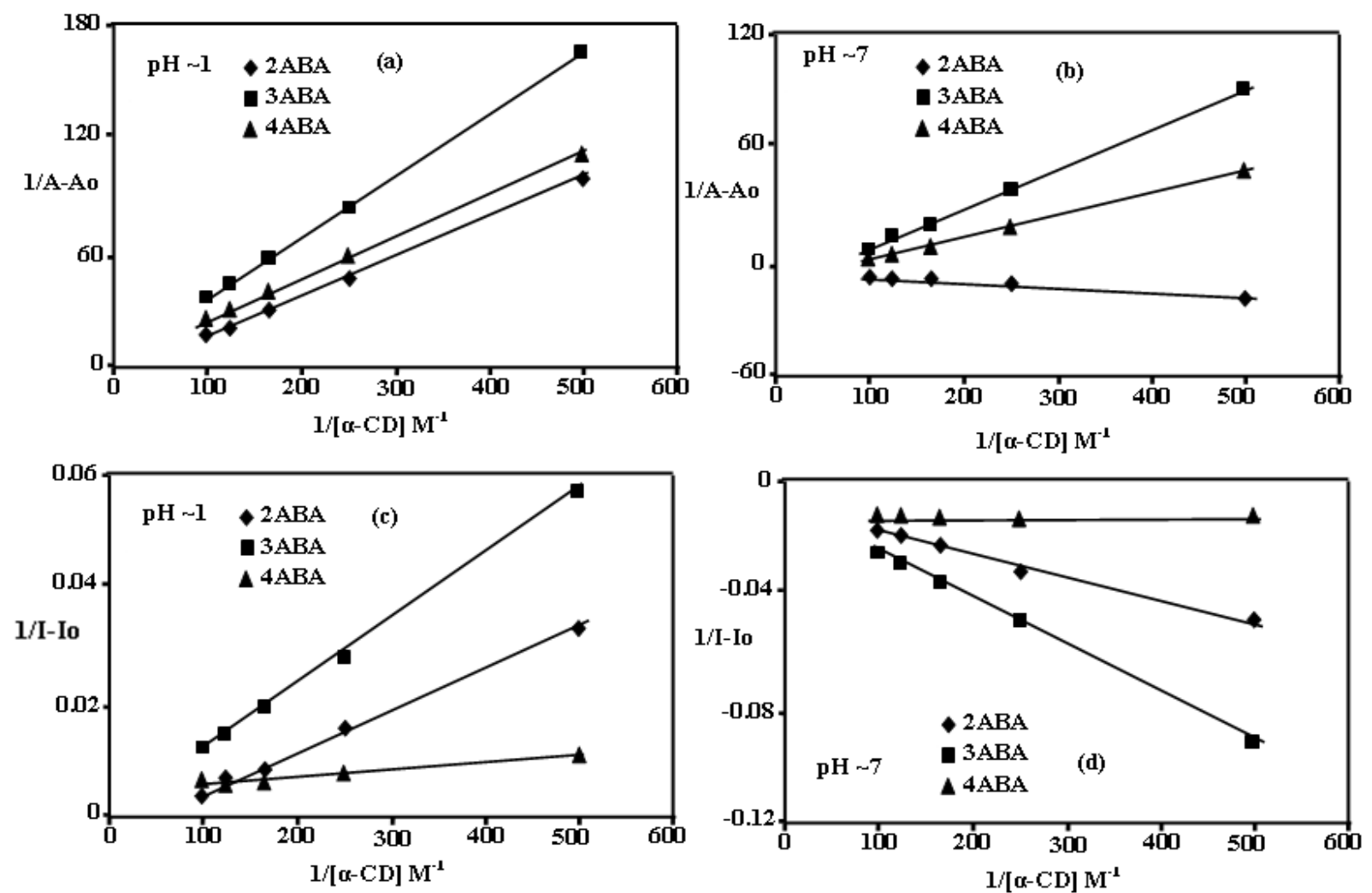

Fig 7. Benesi-Hildebrand plot for 1:1 inclusion complexation of ABAs with $\alpha-C D$ at different pHs:

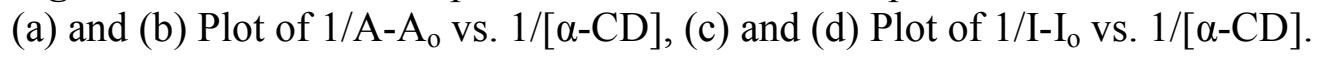



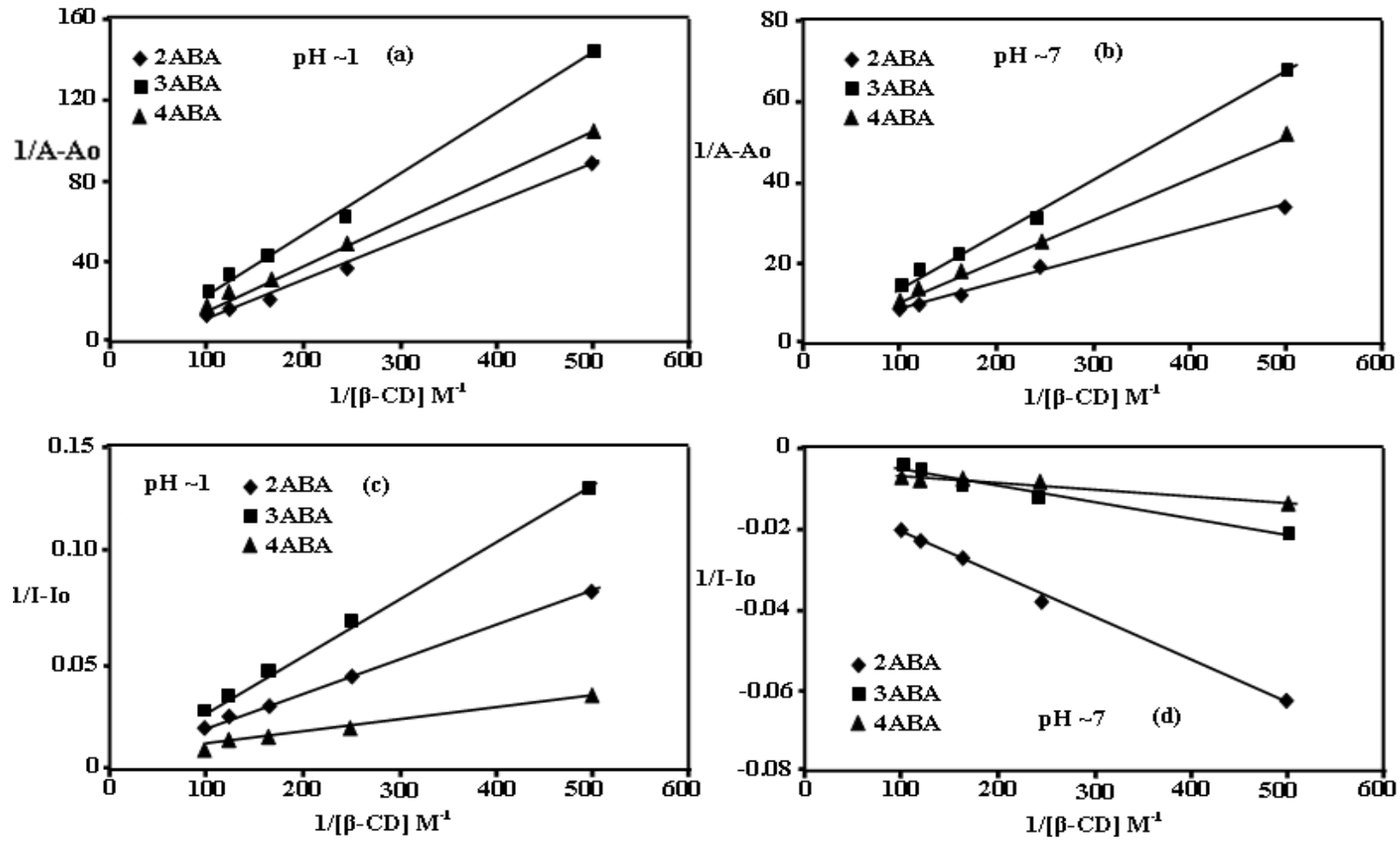

Fig 8. Benesi-Hildebrand plot for $1: 1$ inclusion complexation of $A B A s$ with $\beta-C D$ at different $p H s$ : (a) and (b) Plot of 1/A-Ao vs. 1/[ $\beta$-CD], (c) and (d) Plot of 1/I-Io vs. $1 /[\beta-C D]$.
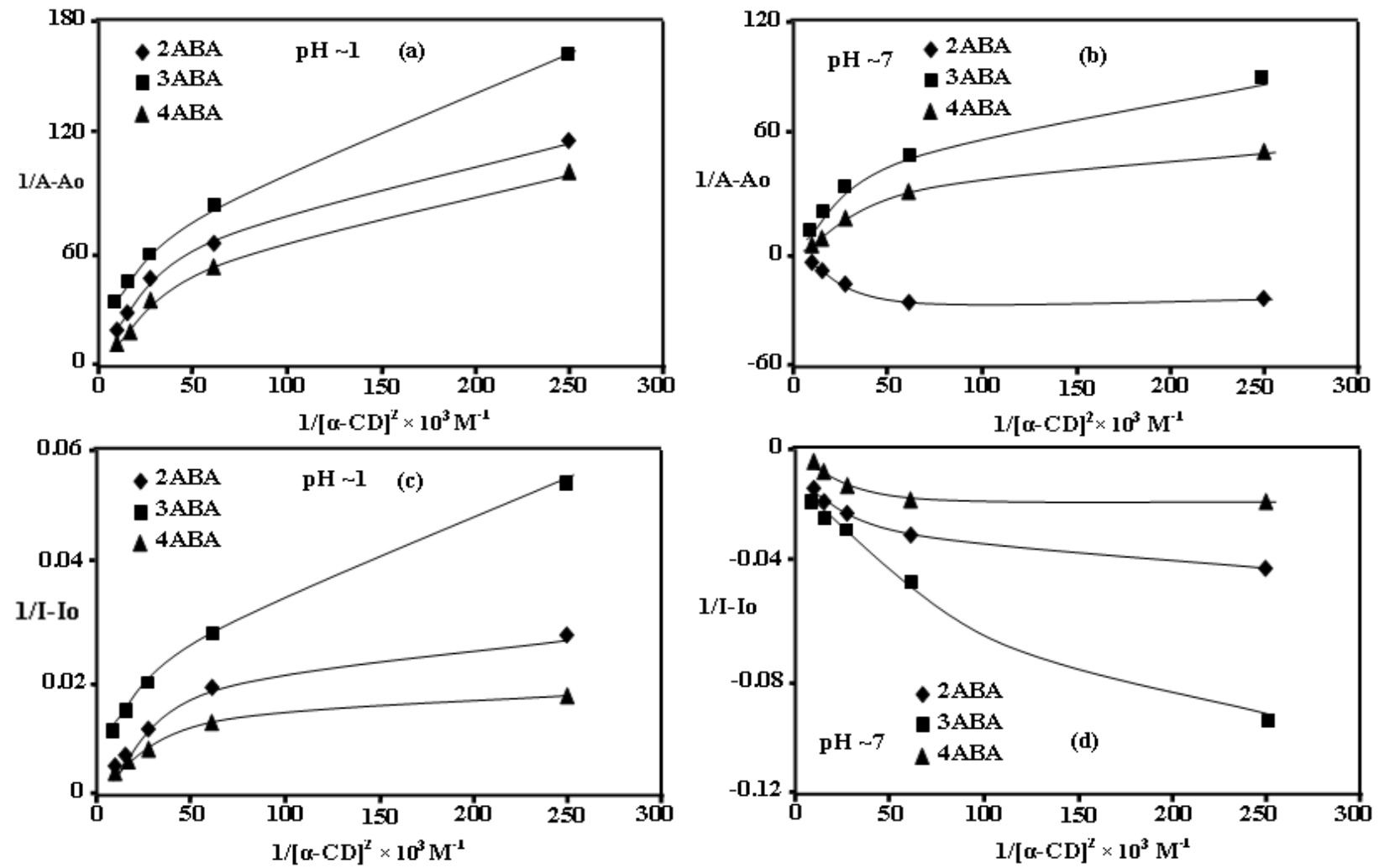

Fig. 9. Benesi-Hildebrand plot for 1:2 inclusion complexation of ABAs with $\alpha$-CD at different pHs: (a) and (b) Plot of 1/A-Ao vs. $1 /[\alpha-C D] 2$, (c) and (d) Plot of 1/I-Io vs. 1/[ $\alpha-C D] 2$. 

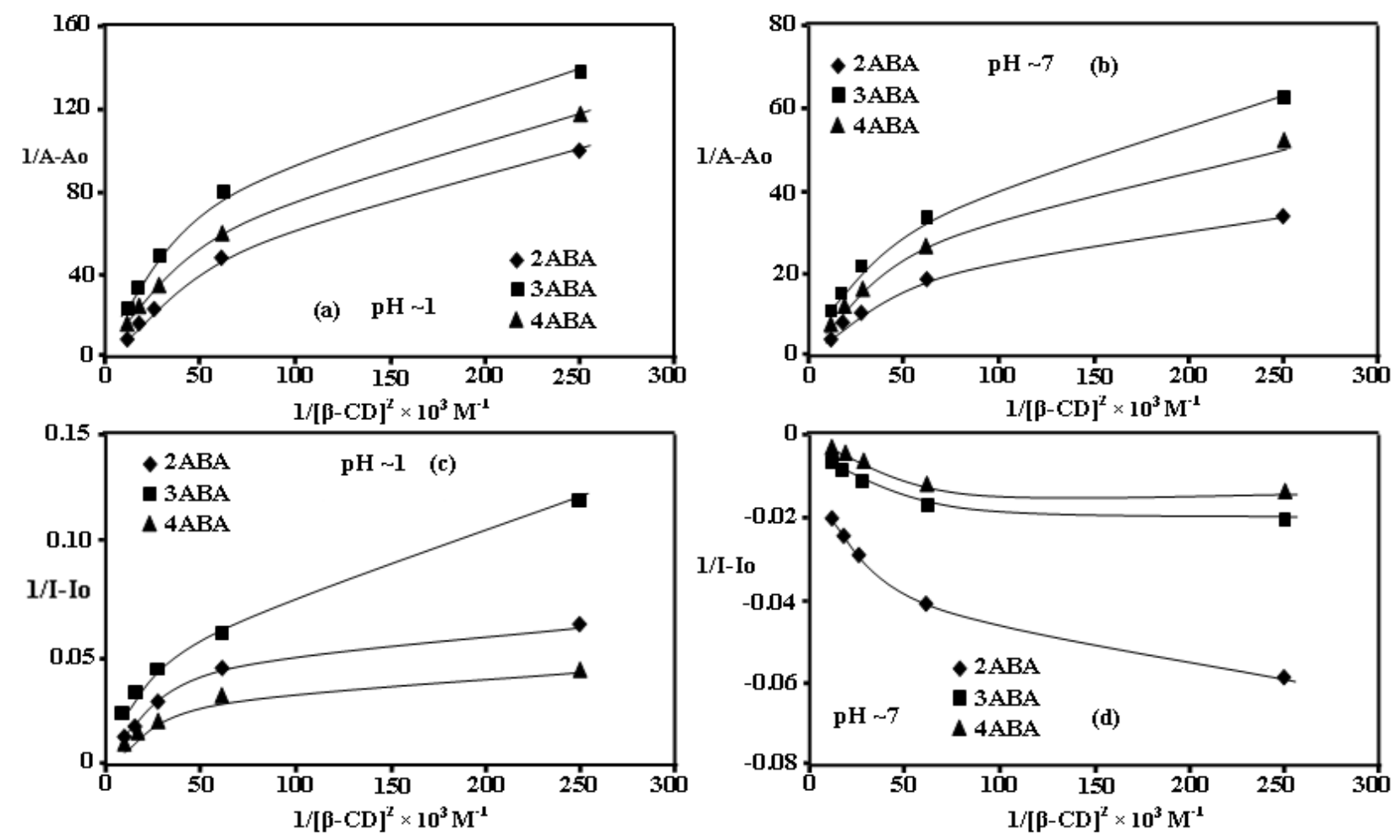

Fig 10. Benesi-Hildebrand plot for $1: 2$ inclusion complexation of $A B A s$ with $\beta-C D$ at different

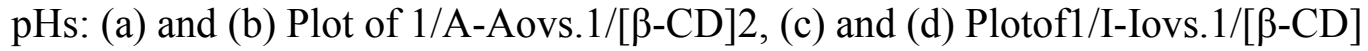

However, at $\mathrm{pH} \sim 7$, in the CDs solutions, no clear isosbestic point was observed in the absorption spectra and thus one can rule out the possibility of the formation of a well-defined 1:1 complex. The absorption and emission spectra of $\mathrm{pH} \sim 1$ and $\mathrm{pH} \sim 7$ solutions were different from the other which indicates the existence of at least two kinds of inclusion complexes in this system.

The formation of 1:1 and 1:2 guest: host inclusion complex, the binding constant can be obtained by using the Benesi-Hildebrand equation for the 1:1 complex and the 1:2 complex between ABAs and CD. A plot of $1 / \mathrm{I}_{0} \mathrm{I}_{0}$ versus $1 /[\mathrm{CD}]$ (both absorption and fluorescence) reveals a linear relation at $\mathrm{pH} \sim 1$ while $\mathrm{pH} \sim 7$ a plot of $1 / \mathrm{I}-\mathrm{I}_{0}$ versus $1 /[\mathrm{CD}]^{2}$ gives a straight line as shown in Figs 7 to 10. 1:1 inclusion complex gives straight line at $\mathrm{pH} \sim 1$, suggesting that the stoichiometry of the inclusion complex 1:1 is present in the ABA molecules. For $\mathrm{pH} \sim 1$, the Benesi-Hildebrand plot fits a 1:1 model. In the case of $\mathrm{pH} \sim 7$, the results are incompatible with a simple 1:1 association model and the formation of 1:2 complexes must be considered, because the red shift of the spectrum and the increase of absorptivity generally observed for the 1:2 complexes. A comparison of these results suggests the following assignments: (i) linear relation observed in $\mathrm{pH} \sim 1$ (Figs. 7 to 10) indicates 1:1 inclusion complexes were formed in this $\mathrm{pH}$, (ii) a concave curve observed in the BenesiHildebrand plot (Figs.7 to 10) indicates 1:2 inclusion complexes were formed in $\mathrm{pH} \sim 7$.

In 1:2 inclusion complexes, the aromatic moieties were partly embedded in the CDs cavity and the amino group forms hydrogen bonding with other $\mathrm{CD}-\mathrm{OH}$ groups. Such a 1:2 inclusion complex structure gains further stabilization energy by hydrogen bonding between hydroxy groups of the primary and secondary rims of the two different CD molecules; water should be excluded from such a structure, although the small solvent molecule could penetrate the central cavity to interact with the amino group. At high $\mathrm{CD}$ concentration, $\mathrm{ABAs}$ are bound to two $\mathrm{CD}$ molecules. This could explain the different interactions of absorption/ emission spectra observed for $\mathrm{pH} \sim 1$ and $\mathrm{pH} \sim 7$ solutions. The red shifts observed for the 1:2 complexes indicate that the ABAs form strong hydrogen bonds, most likely to oxygen of the glucosidic link of the CDs, but renders hydrogen bonds, where the substrate is the proton acceptor unlikely. This analysis reflects the formation of $1: 1$ inclusion complex in $\mathrm{pH} \sim 1$ and mixture of $1: 1$ and 1:2 inclusion complexes with $\mathrm{ABA}: 2 \mathrm{CD}$ in $\mathrm{pH} \sim 7$ solution. The binding constants obtained from the absorbance and fluorescence intensity are 
considerably different from each other again supported the formation for two different complexes between the $\mathrm{ABAs}$ and the $\mathrm{CDs}$ at $\mathrm{pH} \sim 1$ and $\mathrm{pH} \sim 7$ solutions. The binding constants were very sensitive to change of $\mathrm{pH}$ values, which further supported the selective inclusion associated with the monocation and neutral form of ABAs.

Of the two species (monocation and neutral form), we should note that all the CDs can readily include the protonated species than the anionic species, because in the anionic species amino group can interact with $\mathrm{CD}-\mathrm{OH}$ groups than protonated $\mathrm{NH}_{3}{ }^{+}$species. It is well known that substituents of aromatic rings capable of $\mathrm{H}$-bonding can bind the $\mathrm{OH}$ groups of the $\mathrm{CD}$ edges. The energy involved in such H-bond interactions is responsible for the higher binding constants found, when compared to those of the unsubstituted molecule. By assuming this orientation for the ABA molecules in the CDs cavities are easy, because the CDs cavities favour the hydrophobic form of the benzoic acid derivatives [24]. The higher formation constants in $\mathrm{pH} \sim 1$ imply that the $\mathrm{NH}_{3}^{+}$group is more easily embedded in all the CDs cavities than the $\mathrm{COOH}$ group of ABAs. This suggests, $\mathrm{NH}_{3}^{+}$group is present in the interior of the CDs cavities, whereas $\mathrm{COOH}$ group is present within the upper part of the CDs cavities. The absorption and emission spectral red shifts of ABAs at $\mathrm{pH} \sim 7$, in all the CDs suggest that amino group is located within the polar cavity, whereas blue shift emission at $\mathrm{pH} \sim 1$ shows $\mathrm{COOH}$ group is located in non-polar part of the CDs.

This is further supported by using PM3 calculations. PC-model program was used to find out the geometry of the inclusion complexes. This program helped us to draw the structures of the inclusion complexes. The ground state geometries of all the ABA's and the CDs were optimized using PM3 method. This method provides acceptable approximations to give results, which are quite close to the experimental finding. Considering the shape and dimensions of the CDs, ABAs can completely be encapsulated with the $\beta-\mathrm{CD}$ cavity when compared with than $\alpha-\mathrm{CD}$. The distance between $2 \mathrm{ABA}=\mathrm{H}_{5}-\mathrm{H}_{8}$ is $5.96 \AA$ and $\mathrm{H}_{4}-\mathrm{O}_{2}$ is $6.27 \AA$ and $\mathrm{O}_{1}-\mathrm{H}_{4}$ is $6.04 \AA ; \mathbf{3 A B A}=\mathrm{H}_{7}-\mathrm{H}_{8}$ $=5.77, \mathrm{H}_{2}-\mathrm{H}_{6}=4.32, \mathrm{H}_{7}-\mathrm{H}_{9}=6.91, \mathrm{O}_{2}-\mathrm{H}_{9}=5.94, \mathrm{H}_{7}-\mathrm{H}_{5}=6.53, \mathrm{O}_{1}-\mathrm{H}_{8}=6.20$. These values are less than that the inside $\beta$-CD cavity $(6.5 \AA)$, but higher than $\alpha-C D(5.7 \AA)$. Since the length of ABAs is lower than the upper/lower rim value of $\mathrm{CD}$, the amino and carboxylic groups attached benzene ring may be present inside the CD cavity. These findings reveal that ABAs molecules are encapsulated in the $\beta$-CD cavity. The thermodynamic parameter $\Delta \mathrm{G}$ for the association of the guest molecule to $\mathrm{CD}$ is given in Tables 6.1.1 to 6.1.3. As can be seen from Tables, $\Delta \mathrm{G}$ is negative which suggests that the inclusion process proceeded spontaneously at $303 \mathrm{~K}$.

\subsection{Fluorescence lifetime}

The excited state decay curves for monocation (MC), neutral (N) and monoanion (MA) of 2ABA, 3ABA and 4ABA were measured in water and CD medium. Table 2 summarizes the lifetime data for the emission of three species in the CD concentrations. Time resolved analyses of the fluorescence decays indicate that all three species are triexponential in water and CD environments, whereas in 4ABA the different type of decay was observed in both mediums. From the observation of absorption and fluorescence data, the intramolecular charge transfer was observed in water and $\mathrm{CD}$ for $2 \mathrm{ABA}$ and $3 \mathrm{ABA}$. The lifetimes of the ionic species in $\mathrm{CD}$ are longer than those observed in aqueous medium. The increase in the value of lifetime with an increase in $\mathrm{CD}$ concentration is due to the encapsulation of all species in the CD cavity. 
Table 2. Fluorescence lifetime parameters of $2 \mathrm{ABA}, 3 \mathrm{ABA}$ and $4 \mathrm{ABA}$ in water and $\alpha$-, $\beta$-cyclodextrins.

\begin{tabular}{|c|c|c|c|c|c|c|c|c|}
\hline \multirow[t]{2}{*}{ Compound } & \multirow[t]{2}{*}{ CDs } & \multicolumn{3}{|c|}{ Lifetime (ns) } & \multicolumn{3}{|c|}{ Pre-exponential factor } & \multirow[t]{2}{*}{$<\tau>$} \\
\hline & & $\tau_{1}$ & $\tau_{2}$ & $\tau_{1}$ & $a_{1}$ & $a_{2}$ & $a_{3}$ & \\
\hline \multirow[t]{6}{*}{$2 \mathrm{ABA}$} & pH 1 & 0.40 & 2.11 & 10.21 & 11.32 & 15.25 & 73.43 & 4.16 \\
\hline & $\mathrm{pH} 1-\alpha-\mathrm{CD}$ & 0.42 & 2.15 & 11.34 & 17.22 & 26.16 & 56.62 & 4.22 \\
\hline & $\mathrm{pH} 1-\beta-\mathrm{CD}$ & 0.45 & 2.19 & 15.68 & 38.08 & 51.53 & 10.39 & 4.38 \\
\hline & $\mathrm{pH} 7$ & 0.46 & 2.24 & 12.33 & 13.11 & 17.45 & 69.44 & 3.65 \\
\hline & pH $7-\alpha-C D$ & 0.49 & 2.28 & 14.90 & 19.40 & 29.32 & 51.28 & 3.67 \\
\hline & $\mathrm{pH} 7-\beta-\mathrm{CD}$ & 0.52 & 2.32 & 17.45 & 39.23 & 54.65 & 6.12 & 3.72 \\
\hline \multirow[t]{6}{*}{$3 \mathrm{ABA}$} & $\mathrm{pH} 1$ & 0.46 & 2.61 & 13.01 & 2.83 & 5.76 & 91.41 & 4.32 \\
\hline & $\mathrm{pH} 1-\alpha-\mathrm{CD}$ & 0.29 & 1.56 & 14.65 & 7.10 & 16.23 & 76.67 & 4.39 \\
\hline & $\mathrm{pH} 1-\beta-\mathrm{CD}$ & 0.37 & 1.97 & 80.90 & 28.08 & 41.53 & 30.38 & 4.44 \\
\hline & pH 7 & 0.52 & 1.98 & 10.26 & 5.67 & 8.32 & 86.01 & 3.88 \\
\hline & $\mathrm{pH} 7-\alpha-\mathrm{CD}$ & 0.55 & 2.02 & 12.20 & 7.10 & 16.23 & 76.67 & 3.93 \\
\hline & $\mathrm{pH} 7-\beta-\mathrm{CD}$ & 0.56 & 2.05 & 14.27 & 28.08 & 41.53 & 30.38 & 3.95 \\
\hline \multirow[t]{6}{*}{$4 \mathrm{ABA}$} & $\mathrm{pH} 1$ & 0.06 & 1.55 & 8.01 & 90.72 & 3.43 & 5.85 & \\
\hline & pH $1-\alpha-C D$ & 0.40 & & & 100 & & & \\
\hline & $\mathrm{pH} 1-\beta-\mathrm{CD}$ & 0.71 & & & 100 & & & \\
\hline & $\mathrm{pH} 7$ & 0.08 & 1.76 & 8.19 & 87.56 & 11.11 & 1.33 & \\
\hline & $\mathrm{pH} 7-\alpha-\mathrm{CD}$ & 0.55 & & & 100 & & & \\
\hline & $\mathrm{pH} 7-\beta-\mathrm{CD}$ & 0.80 & 1.69 & & 91.23 & 8.77 & & \\
\hline
\end{tabular}

\section{Conclusion}

The following conclusions can be arrived at from the above studies: (i) the observation of a large red shifted absorption and emission maxima even in nonpolar solvents indicates that ICT is present along with IHB, (ii) zwitter ion exists only in the ground state, (iii) due to steric effect, the monocation $\left(\mathrm{NH}_{3}{ }^{+}\right)$and carboxyl groups are twisted in the $\mathrm{S} 1$ state, (iv) All the ABAs form 1:1 complex at $\mathrm{pH} \sim 1$ solution and mixture of 1:1 and 1:2 complex at $\mathrm{pH} \sim 7$ with all the four $\mathrm{CD},(\mathrm{v})$ dual luminescence appeared at $\mathrm{pH} \sim 1$ indicates, both $\mathrm{NH} 3+$ and $\mathrm{COOH}$ groups are present in the interior of the CDs cavities, (vi) FT-IR, 1H NMR, results suggest ABAs formed a stable inclusion complex with the CDs and (vii) the above studies demonstrate that in 2ABA and 3ABA, ICT interactions play a significant role in the inclusion complexes.

\section{Acknowledgement}

This work is supported by the CSIR [No. 01(2549)/12/ EMR-II], and UGC [F.No. 41-351/2012 (SR)]. The authors thank to Dr. P. Ramamurthy, Director, National centre for ultrafast processes, Madras University for allowing the fluorescence lifetime measurements available for this work.

\section{References}

[1] L. Doub, J.M. Vandenbelt, The Ultraviolet Absorption Spectra of Simple Unsaturated Compounds. I. Mono- and p-Disubstituted Benzene Derivatives, J. Am. Chem. Soc. 69 (1947) 2714-2723.

[2] V.G. Plotnikov, V.M. Komarov, Theoretical Interpretation of Luminescent Properties of Nitroanilines, Spectrosc. Lett. 9 (1976) 265-278.

[3] T.N. Kopylova, Study of the adsorption of organic substances on platinum by the impedance measurement method, Zh. Fiz. Khim. 51 (1977) 1601-1609.

[4] N. Mataga, Solvent Effects on the Absorption and Fluorescence Spectra of Naphthylamines and Isomeric Aminobenzoic Acids Bull. Chem. Soc. Jpn. 36 (1963) 654.

[5] A. Tramer, Tautomeric and protolytic properties of o-aminobenzoic acids in their lowest singlet and triplet states, J. Phys. Chem. 74 (1970) 887-894. 
[6] D.V.S. Jain, F.S. Nandel, P. Singla, D.J. Kaur, Experimental and theoretical studies on electronic spectra of $\mathrm{o}-, \mathrm{m}$-and $\mathrm{p}$-aminobenzoic acids and their protonated and deprotonated species, Ind. J. Chem. 25A (1986) 15-19.

[7] A. Antony Muthu Prabhu, R.K. Sankaranarayanan, S. Siva, N. Rajendiran, Unusual spectral shifts on fast violet-B and benzanilide: Effect of solvents, $\mathrm{pH}$ and beta-cyclodextin, Spectrochimica Acta. 74A (2009) 484-497.

[8] A. Antony Muthu Prabhu, G. Venkatesh, N. Rajendiran, Azo-hydrazo Tautomerism and Inclusion Complexation of 1-phenylazo-2-naphthols with Various Solvents and $\beta$-cyclodextrin, J. Floures. 20 (2010) 961-972.

[9] A. Antony Muthu Prabhu et al., Spectral characteristics of 2-amino-3-benzyloxy pyridine: Effects of solvents, pH, and $\beta$-cyclodextrin, Russian. J. Phys. Chem. A. 84 (2010) 2270-2283.

[10] T.B. Jiang, Effect of cyclodextrin inclusion complex formation on the twisted intramolecular charge transfer (TICT) of the included compound: the $p$-dimethylaminobenzoic acid- $\beta$-cyclodextrin system, J. Photochem. Photobiol. A: Chem. 88 (1995) 109-116.

[11] H.R. Park, B. Mayer, P. Wolschann, G. Kohler, Excited-State Proton Transfer of 2-Naphthol Inclusion Complexes with Cyclodextrins, J. Phys. Chem. 98 (1994) 6158-6166.

[12] T. Sivasankar, A. Antony Muthu Prabhu, M. Karthick, N. Rajendiran, Encapsulation of vanillylamine by native and modified cyclodextrins: Spectral and computational studies, J. Mol. Struc. 1028 (2012) 57-67.

[13] A. Antony Muthu Prabhu, S. Siva, R.K. Sankaranarayanan, N. Rajendiran, Intramolecular Proton Transfer Effects on 2,6-diaminopyridine. J. Fluoresc. 20 (2010) 43-54.

[14] A. Antony Muthu Prabhu et al., Azonium-ammonium tautomerism and inclusion complexation of 4-amino-2',3-dimethylazobenzene. Ind. J. Chem. 49A (2010) 407-417.

[15] R.K. Sankaranarayanan et al., Dual fluorescence of dothiepin, doxepin drugs-effect of solvents and $\beta$-cyclodextrin. J. Mol. Liq. 161 (2011) 107-114.

[16] A. Antony Muthu Prabhu, V.K. Subramanian, N. Rajendiran, Excimer formation in inclusion complexes of $\beta$-cyclodextrin with salbutamol, sotalol and atenolol: Spectral and molecular modeling studies. Spectrochim. Acta A, 96 (2012) 95 -107.

[17] R. K. Sankaranarayanan, S. Siva, A. Antony Muthu Prabhu, N. Rajendiran, A study on the inclusion complexation of 3,4,5-trihydroxybenzoic acid with b-cyclodextrin at different $\mathrm{pH}$, J. Incl. Phenom. Macrocycl. Chem. 67 (2010) 461-470.

[18] G. Venkatesh, A. Antony Muthu Prabhu, N. Rajendiran, Azonium-Ammonium Tautomerism and Inclusion Complexation of 1-(2,4-diamino phenylazo) Naphthalene and 4-aminoazobenzene. J. Fluoresc. 21 (2011) 1485-1497.

[19] A. Antony Muthu Prabhu, R.K. Sankaranarayanan, S. Siva, N. Rajendiran, Unusual spectral shifts on fast violet-B and benzanilide: Effect of solvents, $\mathrm{pH}$ and $\beta$-cyclodextin Spectrochim. Acta A. 74 (2009) 484-497.

[20] A. Antony Muthu Prabhu, R. K. Sankaranarayanan, G. Venkatesh, N. Rajendiran, Dual Fluorescence of Fast Blue RR and Fast Violet B: Effects of Solvents and Cyclodextrin Complexation. J. Phys. Chem. B, 116 (2012) 9061-9074.

[21] A. Antony Muthu Prabhu, N. Rajendiran, Encapsulation of Labetalol, Pseudoephedrine in $\beta$ cyclodextrin Cavity: Spectral and Molecular Modeling Studies. J. Fluoresc. 22 (2012) 1461-1474.

[22] J. Premakumari et al., Spectral characteristics of sulphadiazine, sulphisomidine: effect of solvents, $\mathrm{pH}$ and $\beta$-cyclodextrin. Phys. Chem. Liq. 49 (2011) 108-132.

[23] A. Antony Muthu Prabhu, G. Venkatesh, N. Rajendiran, Spectral Characteristics of Sulfa Drugs: Effect of Solvents, pH and $\beta$-Cyclodextrin. J. Solution Chem. 39 (2010) 1061-1086.

[24] A. Sytnik, C.D. Valle, Steady-State and Time-Resolved Study of the Proton-Transfer Fluorescence of 4-Hydroxy-5-azaphenanthrene in Model Solvents and in Complexes with Human Serum Albumin, J. Phys. Chem. 99 (1995) 13028-13032. 